\title{
Repositioning therapy for thyroid cancer: new insights on established medications
}

\section{Yevgeniya Kushchayeva ${ }^{1}$, Kirk Jensen, Kenneth D Burman ${ }^{1}$ and Vasyl Vasko}

Department of Pediatrics, Uniformed Services University of the Health Sciences, 4301 Jones Bridge Road, Bethesda, Maryland 20814-4712, USA

${ }^{1}$ Division of Endocrinology, Department of Medicine, Washington Hospital Center, 110 Irving Street Northwest, Washington, District of Columbia, USA
Correspondence should be addressed to V Vasko Email vasyl.vasko@usuhs.edu

\begin{abstract}
Repositioning of established non-cancer pharmacotherapeutic agents with well-known activity and side-effect profiles is a promising avenue for the development of new treatment modalities for multiple cancer types. We have analyzed some of the medications with mechanism of action that may have relevance to thyroid cancer (TC). Experimental in vitro and in vivo evidences, as well as results of clinical studies, have indicated that molecular targets for medications currently available for the treatment of mood disorders, sexually transmitted diseases, metabolic disorders, and diabetes may be active and relevant in TC. For instance, the derivatives of cannabis and an anti-diabetic agent, metformin, both are able to inhibit ERK, which is commonly activated in TC cells. We present here several examples of well-known medications that have the potential to become new therapeutics for patients with TC. Repositioning of established medications for the treatment of TC could broaden the scope of current therapeutic strategies. These diverse treatment choices could allow physicians to provide an individualized approach to optimize treatment for patients with TC.
\end{abstract}

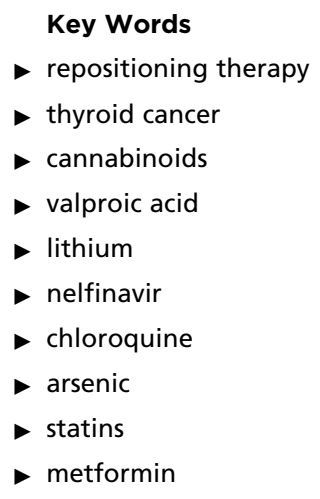

Endocrine-Related Cancer (2014) 21, R183-R194

\section{Introduction}

Thyroid cancer (TC) is the most common endocrine malignancy. An estimated, 60220 new cases of TC and 1850 TC-related deaths are expected in 2013 in the USA. Survival of patients with TC depends upon multiple factors, including cancer type and stage. The 5 -year survival rate is more than $90 \%$ in patients with localized papillary thyroid cancer (PTC) and follicular thyroid cancer (FTC), and only 53.9\% in patients with distant metastases (Schlumberger 1998). The prognosis for patients with medullary thyroid cancer (MTC) depends on the stage of tumor progression at the time of diagnosis, with a mean 10-year survival rate of 100, 93, 71, and
$21 \%$ for stages I, II, III, and IV respectively (Modigliani et al. 1998).

An increasing number of phase I and II studies have been conducted to evaluate the efficacy of new molecular targeted drugs, such as tyrosine kinase inhibitors, inhibitors of angiogenesis, radio-immunotherapy, and re-differentiation drugs (Lanzi et al. 2009, Liebner \& Shah 2011). Several targeted therapies have shown promising biochemical response and have resulted in the inhibition of targeted signaling pathways in TC cells. Most of these therapeutic modalities, however, were associated frequently with high toxicity rates.

Published by Bioscientifica Ltd. 
The identification of novel drug targets is a significant challenge in drug development. Although the human genome comprises $\sim 30000$ genes, only the proteins encoded by fewer than 400 are used as drug targets (Rask-Andersen et al. 2011). Drug discovery is still a very lengthy, as well as an increasingly risky and costly process. It is estimated to cost around $\$ 1$ billion per medication and the process takes $\sim 15$ years from conception to Food and Drug Administration (FDA) approval (Dickson \& Gagnon 2004).

One method to accelerate development and reduce costs is to identify novel indications for already approved medications, also referred to as 'repositioning' ( $\mathrm{O}$ 'Connor $\&$ Roth 2005). Repositioning takes advantage of the available pharmacokinetic and toxicity data on existing drugs, limits risks and costs, and could accelerate the implementation of new cancer therapies. There already has been successful repositioning of the existing drugs for the treatment of cancer, including i) cyclooxygenase-2 inhibitors, which are FDA-approved anti-inflammatory drugs and are now approved for cancer chemoprevention in familial adenomatous polyposis patients; and ii) lenalidomide, originally marketed for morning sickness, which is now approved for treatment of myelodysplastic syndromes (Li \& Jones 2012). In addition, a well-known and widely used oncology agent, gemcitabine, was developed initially as an antiviral drug, but was later repositioned for the treatment of cancer.

The unexpected side effects observed during clinical trials and off-target toxicity frequently lead to repositioning toward the non-intended use of the drug. For example, Sildenafil (Viagra; Pfizer), was initially developed as an anti-angina medication, but produced the remarkable side effect of inducing prolonged penile erections in human volunteers (Ashburn \& Thor 2004). A further approach used to reposition medications is the use of high-throughput screening using drug libraries and computational network analysis. Recent studies have shown that these experimental methods enable the prediction of novel drug targets and the repositioning of known drugs for the treatment of cancer (Shim et al. 2012, Emig et al. 2013).

Studies of the molecular mechanisms of TC have provided the basis for the development of new diagnostic tools, identification of prognostic markers, and markers of response to the treatment (Ringel 2000, 2009, Xing et al. 2005, Nikiforov 2008). Novel insights into the molecular pathology of TC revealed a number of potential cancer drivers that were already explored in the context of nonTC pathology. In TC, a high-throughput screening of 2816 clinically approved drugs demonstrated that medications with non-classic chemotherapy mode of action (cardiotonic, antilipid, and antiviral medications) inhibited the growth of TC cells (Zhang et al. 2012), suggesting their possible repositioning for the treatment of TC.

In this review, we will discuss several specific examples of repositioning efforts that have been focused on TC, with data suggesting the potential efficacy of psychoactive compounds, medications intended for the treatment of infectious and metabolic diseases, as well as a commonly used anti-diabetic drug for the treatment of TC.

\section{Psychoactive compounds and mood stabilizers}

\section{Lithium}

The mood stabilizer lithium ( $\mathrm{Li}$ ) is primarily used to treat bipolar disorder, a common mental illness that affects $\sim 1-3 \%$ of the population. Accumulating evidence indicates that this agent also holds promise for treating neurologic and/or neurodegenerative diseases via its diverse mechanisms of action.

At therapeutic serum concentrations (0.6-1.2 mM), $\mathrm{Li}$ is known to inhibit a group of phosphomonoesterases, the metabolic enzyme phosphoglucomutase, and GSK3b. Moreover, activation of the phosphoinositol cascade, adenylate cyclase, and metabolism of arachidonic acid are also affected by Li. The protein GSK3b is believed to be the main facilitator of Li's mood-stabilizing and neuroprotective effects (Chiu et al. 2013).

Thyroid abnormalities such as goiter, hypothyroidism, and autoimmune thyroiditis have been reported to be associated with treatment with Li (Bocchetta et al. 2007). Li has been shown to be highly concentrated in thyroid cells, achieving levels 3-4 times more than that observed in the serum. To explain the mechanism of Li action in the thyroid gland, the effects of Li on thyroid function and cell growth were examined in FRTL-5 rat thyroid cells and in primary cultures of porcine thyroid follicles. Li suppressed TSH-induced iodide uptake, reduced iodine organification, and de novo thyroid hormone formation. In both FRTL-5 thyroid cells and porcine follicles, Li enhanced cell growth: its growth-promoting effect was mediated through the protein kinase C system (Urabe et al. 1991). In vivo studies have shown that $\mathrm{Li}$ inhibits the release of iodine from the thyroid.

The effects of $\mathrm{Li}$ on the accumulation and retention of 131-I in metastatic lesions and thyroid remnants were evaluated in patients with differentiated thyroid

Published by Bioscientifica Ltd 
carcinoma (Koong et al. 1999). From a series of gamma-camera images, it was found that $\mathrm{Li}$ increased 131-I retention in 24 of 31 metastatic lesions and in six of seven thyroid remnants. Li prolonged the effective halflife in responding metastases by more than $50 \%$ and increased the estimated 131-I radiation dose in metastatic tumor by 2.29 times. These studies suggest that Li may be a useful adjuvant for 131-I therapy of TC, augmenting both the accumulation and retention of 131-I in lesions. Shortterm Li therapy is well tolerated by most individuals, and no serious toxicity in patients with TC was reported in the literature. Among adverse effects, gastrointestinal disturbances (nausea, vomiting, diarrhea) were reported in $10-20 \%$ of patients, but were usually mild and did not require discontinuation of the drug (Pons et al. 1987).

It has been shown that raf-1-inducible activation of ERK in MTC cells increased phosphorylation of GSK3b (Kunnimalaiyaan et al. 2007). Treatment with Li inhibited phosphorylation of GSK3b and led to the inhibition of MTC cell growth. Growth inhibition by GSK3b inactivation was found to be associated with cell cycle arrest due to an increase in the levels of cyclin-dependent kinase inhibitors such as p21, p27, and p15. Furthermore, Li-treated MTC xenografts had a significant reduction in tumor volume compared with those treated with control.

These results showed that inactivation of GSK3b is sufficient to inhibit the growth of MTC cells in vitro and in vivo, and currently the effects of Li on residual/ recurrent MTC are being evaluated in a clinical trial (NCT00582712). There is a clinical trial evaluating the effect of $\mathrm{Li}$ on low-dose 131-I therapy in early TC (NCT00251316).

\section{Valproic acid}

Valproic acid (VA) is an established agent for the treatment of epileptic seizures and mania in bipolar disorder. In the human brain, VA affects the function of neurotransmitter GABA by inhibition of GABA degradation, increased GABA synthesis, and decreased GABA turnover (Barrueto et al. 2002). VA is an effective epigenetic modulator that causes $\mathrm{N}$-terminal tail hyperacetylation of histones and inhibits histone deacetylase (HDAC) enzymatic activity. Chromatin remodeling by acetylation of the N-terminal histone tails is one of the key steps in the regulation of gene expression in cancer cells (Gottlicher et al. 2001). HDAC inhibitors were found to upregulate pro-apoptotic (Bim, Bmf, Bax, Bak, and Bik) and downregulate anti-apoptotic (Bcl2 family) proteins in various cancer cell lines and in animal cancer models (Xu et al. 2007).
VA demonstrated a wide range of anticancer in vitro effects on prostate, breast, and endometrial cancers, neuroblastoma, glioma, and leukemia, and has been proposed as a re-differentiating agent for hematological malignancy and neuroblastoma (Fortunati et al. 2004, Catalano et al. 2005). Studies in EBV-related cancer cell lines showed that VA induced expression of EBV lyticphase gene and increased the efficacy of chemotherapeutic agents in epithelial and lymphoblastoid cell lines, harboring EBV (Feng \& Kenney 2006).

TC cells are characterized by elevated expression of HDAC compared with normal thyroid tissue (Nakagawa et al. 2007). In vitro studies have shown that while treatment with an HDAC inhibitor affects expression of thyroid-specific genes and I-131 uptake in TC cells (Puppin et al. 2005), VA selectively upregulated expression of NIS, but did not alter Tg production and TSHR expression in PTC and ATC cell lines. In PTC-derived cells, induction of NIS expression was associated with its membrane localization and induction of I-131 uptake. In ATC-derived cells, however, VA-inducible increase in cytoplasmic NIS was not associated with induction of I-131 uptake (Fortunati et al. 2004). VA also was found to inhibit proliferation and induce apoptosis in TC cells. Treatment with VA was associated with increased expression of p21, downregulation of cyclin A, and induction of cell-cycle arrest in G1 phase in PTC-derived cells (Catalano et al. 2005). In FTC- and PTC-derived cell lines, treatment with VA was associated with downregulation of anti-apoptotic genes (BCL2, BCL-xl), upregulation of a pro-apoptotic gene (Perez et al. 2004), and induction of apoptosis (Shen et al. 2005). VA also decreased invasiveness of FTC and PTC-derived TC cells through inhibition of MMP-2 and MMP-9 and sensitized ATC-derived cells to treatment with doxorubicin (Kim et al. 2009, Mitmaker et al. 2011). EBV was detected in poorly differentiated TC, and the expression of EBV nuclear antigen and EBV latent membrane protein was proposed to play a role in the progression of PTC to undifferentiated carcinoma (Shimakage et al. 2003). Presence of viral genome in poorly differentiated TCs suggests that viruses could serve as a target, and further studies are needed to determine whether VA can be clinically useful in patients with EBV-positive thyroid tumors.

The potential utility of VA for the treatment of patients with MTC was suggested in recent studies. VA upregulated Notch1 expression in MTC cells, resulting in growth inhibition and induction of apoptosis (Greenblatt et al. 2007, Adler et al. 2010).

Published by Bioscientifica Ltd 
VA acts as a potent HDAC inhibitor at serum concentrations achievable in patients with epilepsy and produces mild adverse effects. There are 62 clinical trials in which VA is currently being tested as an anti-cancer drug for variety of cancers (Clincaltrials.gov), including advanced TC (NCT01182285).

\section{Cannabis}

Cannabis has been used for medicinal purposes for many years. Several types of medicinal cannabinoids are available in the USA and Canada. Dronabinol (schedule III), nabilone (schedule II), and nabiximols (approved in Canada) are cannabis-derived pharmaceuticals. Dronabinol and nabilone are indicated for the treatment of nausea and vomiting associated with cancer chemotherapy, and of anorexia associated with weight loss in patients with acquired immune deficiency syndrome. The hemp plant Cannabis sativa produces 70 unique compounds known as cannabinoids, of which D9-tetrahydrocannabinol (THC) is the best characterized, owing to its high potency and abundance. THC exerts a wide variety of biological effects by mimicking endogenous substances - the endocannabinoids - anandamide and 2-arachidonoylglycerol - bind to, and activate, specific cannabinoid receptors.

Studies in neuronal cells demonstrated that the endocannabinoid anandamide inhibits activation of ERK kinase via cannabinoid receptor 1 (CB1). Treatment with anandamide inhibited TrkA-induced Rap1/B-Raf/ERK activation (Rueda et al. 2002). In several models, cannabinoid administration has been shown to curb the growth of glioma, astrocytoma, and pancreatic cancer cell lines, and reduced the growth of hepatocellular carcinoma subcutaneous xenografts (Vara et al. 2011). The mechanism of cannabinoid anti-tumoral action relies on the ability of these agents to inhibit tumor angiogenesis and inhibit cell-cycle progression. Cannabinoids activate an endoplasmic reticulum (ER) stress-related signaling route that leads to the upregulation of the transcriptional co-activator $\mathrm{p} 8$ and its target, the pseudo-kinase tribbles homolog 3 (TRB3; Salazar et al. 2009). The stimulation of this pathway promotes autophagy via TRB3-mediated inhibition of the Akt/mammalian target of rapamycin complex 1 (mTORC1) axis and is important for the proapoptotic and anti-tumoral action of THC.

The inhibitory effects of a metabolically stable analog of anandamide (2-methyl-2'-F-anandamide (Met-F-AEA)) were demonstrated in TC cells. The inhibition of TC cell growth was due to an interaction Met-F-AEA with cannabinoid receptor 1 (CB1), activation of p53 signaling, and an increased apoptotic rate. It has also been shown that activation of cannabinoid receptor 2 (CB2) triggers apoptosis in anaplastic TC cell lines. A considerable regression of thyroid tumors generated by inoculation of ARO/CB2 cells was observed in nude mice following administration of CB2 agonist JWH133 (Shi et al. 2008).

Data indicating that endocannabinoids are effective against cancer cells with activated BRAF/ERK and/or TrkA signaling suggest its potential utility for the treatment of BRAF-positive PTC and TrkA-positive MTC. Expression of CB1 and 2, however, has not yet been examined in BRAFpositive human TC tissue samples, and additional studies are needed to determine the expression of endocannabinoid's molecular targets in human thyroid tumors. Given that cannabinoids have shown anti-tumor effects in many types of cancer models, CB2 may be a viable therapeutic target for the treatment of thyroid carcinomas.

\section{Metabolic and anti-diabetic drugs}

\section{Statins}

Statins (lovastatin, simvastatin, pravastatin, and atorvastatin) are a widely used group of cholesterol-lowering agents that act by inhibiting the enzyme 3-hydroxy3-methylglutaryl CoA (HMG-CoA) reductase, which catalyzes the rate-limiting step in cholesterol biosynthesis (Evans et al. 2004). Statins reduce the concentration of mevalonate, which in turn leads to increased LDL-receptor expression in hepatocytes, and to increased LDL-C uptake from the circulation. Results from large, randomized controlled trials have provided evidence that statin treatment reduces the risks of vascular death, myocardial infarction, and stroke (Baigent et al. 2005).

Elevated HMG-CoA reductase activity has been shown in cancer cells, including colorectal and gastric carcinomas and leukemia. Malignant cells appear to be highly dependent on the sustained availability of mevalonate pathway end-products (isoprenoids, farnesyl pyrophosphate, and geranylgeranyl pyrophosphate). These intermediates are critical for the post-translational phenylation of proteins including Ras, Rho, and Rac, which play a role in regulation of cancer cell proliferation, migration, and apoptosis (Zeybek et al. 2011). In vitro studies demonstrated that statins inhibit cancer cell proliferation via Rac-1 as well as through reduction of Rho geranylgeranylation. Most published data, however, emphasizes the effects of statins on cancer cell migration. It has been shown that the ability of statins to block the isoprenylation of Rho protein represents the primary

Published by Bioscientifica Ltd. 
mechanism that affects cell motility. Lovastatin-inducible downregulation of the Rho/ROCK signaling led to the inhibition of phosphorylation of focal adhesion complex (FAK) and paxillin, which are involved in the regulation of stress fibers and focal adhesions (Yasunari et al. 2001). Growth inhibitory effects of statins were explored in combination with classical chemotherapy. It has been shown that the combination of paclitaxel with lovastatin resulted in antagonism that affected both the cytotoxicity of the compounds and apoptosis (Chung et al. 2011), indicating that it is important to examine the compatibility of statins with existing therapy.

Statins were considered for cancer prevention and chemosensitization. Treatment with statins was associated with delayed metastasis of melanoma in a case-control study including 1318 cases and 6786 controls (Koomen et al. 2007). Results of this study, as well as data from epidemiological analysis of breast, prostate, and colon cancers in dyslipidemic patients, suggested the potential protective effects of statins on cancer progression.

In PTC- and ATC-derived TC cell lines, Lovastatin induced cell-cycle arrest in G0/G1 phase, inhibited proliferation, promoted formation of autophagic vesicles, and induced apoptosis (Wang et al. 2003, Zeybek et al. 2011). Pretreatment of ARO cells with a p27, but not p21, anti-sense oligonucleotide prevented the Lovastatininduced G0/G1 arrest in ARO cells. The Lovastatininduced growth inhibition was completely prevented by cell treatment with mevalonate and partially by geranylgeranyl pyrophosphate. Lovastatin increased TC cell differentiation and I-131 uptake, and decreased ATC cell invasion through inhibition of RhoA and Rac1. Animal studies have demonstrated that Lovastatin significantly reduced ATC tumor growth in mice treated with 5 or $10 \mathrm{mg} / \mathrm{kg}$ per day dosage regimens, but enhanced tumor growth when a dose of $1 \mathrm{mg} / \mathrm{kg}$ per day was administered (Wang et al. 2010).

Studies using FRTL-5 thyroid cells demonstrated a differential response to the treatment with Lovastatin in cells that were transformed with K-ras or $\mathrm{H}$-ras viral oncogenes (Laezza et al. 2008). Lovastatin induced apoptosis in K-ras-transformed FRTL-5 cells, but led to cell-cycle arrest in H-ras-transformed FRTL-5 cells. The Lovastatin-induced apoptosis in K-ras-transformed FRTL-5 cells was due to increased intracellular reactive oxygen species, as well as activation of p38 mitogen-activated protein kinase and nuclear factor $\kappa \mathrm{B}$ pathways. Lovastatin anti-tumor efficacy in K-ras-dependent thyroid tumors was further confirmed in vivo, therefore suggesting that statins can represent a novel selective therapeutic tool for tumors harboring K-RAS mutations.

Retrospective analysis of thyroid pathology in dyslipidemic patients showed that use of statins was associated with lower prevalence, lower number, and decreased volume of thyroid nodules, which may be explained by an anti-proliferative and/or pro-apoptotic effect of longterm treatment with statins (Cappelli et al. 2008). There are currently no clinical trials using statins in TC patients, but the data suggest that statins merit further investigation as anti-TC agents.

\section{Metformin}

Metformin is an oral anti-hyperglycemic agent that has been widely used in the management of non-insulindependent diabetes mellitus. Metformin was introduced in 1995 and is the most prescribed anti-diabetic drug in the world. The anti-diabetic effects of metformin are mediated by multiple mechanisms, such as suppression of hepatic gluconeogenesis, increase in peripheral glucose uptake, and reduction in insulin resistance.

The intracellular effects of metformin are mediated by activation of AMP-activated protein kinase AMPK (El-Mir et al. 2000). Studies in breast, prostate, ovarian cancer cell lines, as well as in animal models, demonstrated that metformin inhibits cancer cell growth via AMPKdependent inhibition of the mTOR signaling pathway and inhibition of cyclin D1 expression (Shaw 2009, Ben Sahra et al. 2010, Martin-Castillo et al. 2010). In addition to direct growth inhibitory properties, metformin is able to potentiate the cytotoxic effects of chemotherapeutic compounds through AMPK and p53 signaling (Iliopoulos et al. 2011, Rocha et al. 2011, Petrushev et al. 2012).

Recent epidemiological, animal, and in vitro studies have demonstrated that metformin also has antineoplastic effects in various human cancers. Diabetic patients treated with metformin have a lower risk of cancer than patients not treated with metformin (Evans et al. 2005, Buchs \& Silverman 2011). Growing evidence has emerged that metformin use may reverse the increased cancer risk associated with administration of insulin (Cazzaniga et al. 2009, Lee et al. 2011). A recent metaanalysis has identified a $31 \%$ reduction in overall cancer incidence or mortality when metformin is used in the treatment of diabetes (Cazzaniga et al. 2009). Moreover, observational studies have documented that treatment with metformin is associated with sensitization to neoadjuvant therapy for breast cancer, and prompted phase III clinical trials addressing the role of metformin as

Published by Bioscientifica Ltd. 
an adjuvant therapy for breast cancer patients (Goodwin et al. 2009).

In PTC- and FTC-derived cell lines, metformin inhibited cancer cell growth and downregulated cyclin D1 expression. Interestingly, TC cell treatment with metformin at concentrations that were sufficient for inhibition of cell growth did not affect TC cell migration. Studies of cell signaling activation in metformin-treated cells indicated that activation of AMPK and inhibition of p70S6K/pS6 signaling were common events in all examined TC cells. In an oxidative stress model, metformin potentiated $\mathrm{H}_{2} \mathrm{O}_{2}$-inducible activation of AMPK and attenuated pERK and p70S6K in PTC- and FTC-derived cells. In addition, metformin antagonized the growthstimulatory effect of insulin, inhibited clonal cell growth, reduced TC sphere formation, and potentiated the antimitogenic effect of chemotherapeutic agents, such as doxorubicin and cisplatin, on undifferentiated thyroid carcinoma cells (Chen et al. 2012). In MTC-derived cells, metformin decreased expression of cyclin D1 and inhibited cell growth. Treatment with metformin was associated with inhibition of mTOR/p70S6K/pS6 signaling and downregulation of pERK in MTC-derived TT and MZ-CRC1 cell lines (Klubo-Gwiezdzinska et al. 2012).

Clinical studies demonstrated that treatment with metformin was associated with a decrease in nodule size in patients with multinodular goiter as compared with treatment with levothyroxine alone (Rezzonico et al. 2011). Moreover, there are studies describing TSH suppression in diabetic patients after treatment with metformin (94), and patients with chronic hypothyroidism managed by levothyroxine therapy (Vigersky et al. 2006).

The retrospective analysis of clinicopathological characteristics in diabetic patients with TC showed that tumor size was significantly smaller in metformin-treated compared with the non-metformin groups. A multivariate model revealed that treatment with metformin increased the likelihood of a complete response, and increased progression-free survival in TC patients with diabetes (Klubo-Gwiezdzinska et al. 2013). Together, these data suggest the potential utility of metformin for treatment of TCs.

Metformin is well tolerated and common side effects include diarrhea, nausea, and vomiting (Bolen et al. 2007). Lactic acidosis is a rare complication, and may occur in patients with liver or kidney comorbidities (Khurana \& Malik 2010). Currently, there are 52 clinical trials evaluating the usefulness of metformin as an adjunct treatment for patients with various type of cancer, but no single trial for patients with TC (Clinicaltrials.gov).

\section{Medications for the treatment of infectious diseases}

\section{HIV protease inhibitor Nelfinavir (Viracept)}

Nelfinavir (NFV) was originally designed as a specific HIV protease inhibitor and, since its introduction in 1997, has served as an effective, reliable, and well-tolerated HIV drug. NFV prevents viral replication by inhibiting the activity of HIV1 protease, an enzyme required for the proteolytic cleavage of the viral polyprotein precursors into the individual functional proteins, resulting in the formation of immature non-infectious viral particles (Bardsley-Elliot \& Plosker 2000). Similarly, NFV was found to inhibit in vitro replication of herpes simplex virus and human cytomegalovirus.

Toxicities associated with HIV protease inhibitors include dyslipidemia, insulin resistance, and diabetes. These side effects of NFV were thought to be a consequence of its off-target action on PI3K/AKT signaling pathway, which is frequently activated in cancer. A recent study has shown that NFV acts as an inhibitor of heat shock protein 90 (HSP90) signaling and induces degradation of HSP90 client proteins to include AKT and ERBB2 (Shim et al. 2012). Treatment with NFV also was associated with induction of ER stress, and ER stress markers, such as BiP and phospho-eIF-2 expression, increased following treatment with NFV. It was suggested that targeting the ER stress pathway, thereby shifting the balance between survival and apoptosis using a sustained ER stress inducer (NFV), could become an attractive pharmacological strategy for suppressing cancer cells.

It has been shown that NFV displays potent inhibitory activity on Kaposi's sarcoma, the most common HIVassociated cancer. Subsequent experimental in vitro and in vivo studies have demonstrated inhibitory effects of NFV on the PI3K/AKT signaling pathway in a variety of human cancer cell lines, including breast, lung, and ovarian cancer cells. The average concentration of NFV exhibiting 50\% inhibition of cultured cell growth and ex vivo ovarian cancer cells was $\sim 5$ and $\sim 10 \mu \mathrm{mol} / 1$ respectively. Such concentrations correspond to the $C_{\max }(\sim 7-9 \mu \mathrm{mol} / \mathrm{l})$ for NFV in HIV patients. Experiments with animal models of human cancers have demonstrated that at clinically achievable concentrations, NFV inhibited tumor growth (Pore et al. 2006, Yang et al. 2006, Gills et al. 2007, Shim et al. 2012). NFV contains a unique cis-decahydroisoquinoline2-carboxamide moiety, which may provide the structural basis for its increased efficacy against cancer compared with other HIV protease inhibitors. Experimental evidence

Published by Bioscientifica Ltd 
indicates that NFV is effective against chemotherapyresistant cancer cells and enhances the sensitivity of tumor cells to radiotherapy in vitro and in vivo.

Genetic abnormalities in PI3K/AKT signaling pathway are common in TC, especially in anaplastic thyroid carcinomas (Hou et al. 2007). NFV, with its anti-apoptotic activity, appears to be a promising agent for the treatment of TC. In MTC cells, a recent study has shown that RET kinase is a client protein for HSP90, and RET mutants rely on HSP90 for protein stability. HSP90 blockade by 17-allylamino-17-demethoxygeldanamycin (17-AAG) induces a $26 \mathrm{~S}$ proteasome-dependent degradation of RET mutants (Carlomagno et al. 2004, Alfano et al. 2010), and it is possible that NFV-inducible block of HSP90 could be effective against MTC-derived cells.

NFV is a well-tolerated agent with mild side effects such as diarrhea, nausea, rash, headache, and flatulence (Bruning et al. 2010). The anti-cancer effects of NFV are currently under investigation in 21 clinical trials for treating patients with cervical, pancreatic, lung, renal, rectal, head and neck cancers, hematological malignancies, multiple myeloma, liposarcoma, and glioma (Pan et al. 2012, Rengan et al. 2012). Eleven of these clinical trials are focused on the action of NFV as a radio-sensitizer. There are no active clinical trials examining the effects of NFV on patients with TC.

\section{Anti-malaria drug chloroquine}

Chloroquine (CQ) is a 9-aminoquinoline, specifically synthesized for use as an anti-malarial agent early in the 1930s. Because of its weak base properties, CQ can pass through the lipid cell membrane and preferentially concentrate in acidic cytoplasmic vesicles. The resulting slight elevation of $\mathrm{pH}$ within these vesicles in macrophages or other antigen-presenting cells may influence the immune response to auto-antigens (Fox 1996). It is believed that this lysosomotropic property of CQ underlines its anti-malarial effects. CQ also demonstrated antiinflammatory and immunosuppressive effects, which have been attributed to the suppression of antigen presentation, inhibition of prostaglandin and cytokine synthesis, and the modulation of Toll-like receptors. It also has been proposed to work as an antiviral agent by interfering with protein glycosylation necessary for viral function.

More recently, the ability of CQ to block autophagy by inhibiting lysosomal proteases and autophagosomelysosomal fusion has generated further interest in this drug. The autophagy pathway regulates lysosomal degradation of organelles, and can be stimulated by multiple forms of cellular stress including nutrient deprivation, hypoxia, reactive oxygen species, and DNA damage (Kroemer et al. 2010). Initial research demonstrated that autophagy may function as a tumor suppressor with defects in autophagy predisposing to tumor development in certain mouse models. Conversely, autophagy has also been shown to have protumorogenic roles in promoting therapeutic resistance to cytotoxic chemotherapy as well as cancer cell survival (Mancias \& Kimmelman 2011). As an inhibitor of autophagy, CQ has been used in combination with diverse chemotherapeutic drugs and radiation, and has been shown to enhance tumor cell killing (Wang et al. 2011, Kimura et al. 2013).

Recent studies have shown that autophagy plays a protective role against acute kidney injury, and thus, the use of CQ in combination with anticancer drugs may exacerbate kidney damage (Kimura et al. 2013). It has to be noted that organs in which autophagy plays a homeostatic role, such as the neurons, liver, hematopoietic stem cells, and heart, may be sensitive to the combined use of CQ and anticancer drugs.

A TC study demonstrated that inhibition of autophagy promotes PTC cell resistance to doxorubicin and radiation, and suggested that autophagy activation may be a useful adjunct treatment for patients with PTC that is refractory to conventional therapy (Lin et al. 2009). It also has been shown that an inhibitor of the mTOR signaling (RAD001) induces autophagy, which enhances the therapeutic response to cytotoxic chemotherapy and external beam radiation in PTC (Lin et al. 2010). A recent study has shown that inhibition of autophagy decreased the antiproliferative effects of sunitinib and sorafenib in MTC cells (Lin et al. 2012).

It is likely that the function of autophagy in TC is dynamic, with both pro-tumorigenic and tumor suppressive roles that depend on cell type, tumor stage, and treatment context. Recent studies have demonstrated that oncogenic Ras expression leads to an increase in autophagy and that this upregulation is necessary for survival and transformation. These findings suggest Ras-driven thyroid tumors may be particularly sensitive to autophagy inhibition.

Currently, there are ten clinical trials evaluating the usefulness of CQ as an adjunct treatment for patients with various type of cancer, but no single trial for patients with TC (Clinicaltrials.gov).

\section{Arsenic}

Arsenic has not only been used extensively to treat infectious diseases such as syphilis, plague, and malaria,

Published by Bioscientifica Ltd 
but also been used to commit murder by poisoning. Throughout history, a number of prominent people including Francesco de' Medici, Napoleon Bonaparte, and Simón Bolívar, were poisoned with arsenic compounds.

Arsenic compounds have prominent mitotoxic effects and disrupt ATP production through several mechanisms. At the level of the citric acid cycle, arsenic inhibits pyruvate dehydrogenase, and by competing with phosphate, it uncouples oxidative phosphorylation, thus inhibiting energy-linked reduction of $\mathrm{NAD}+$, mitochondrial respiration, and ATP synthesis (Sun et al. 2011). Hydrogen peroxide production is also increased, which might form reactive oxygen species and produce oxidative stress. These metabolic interferences lead to apoptosis and/or necrotic cell death.

The anti-cancer activity of arsenic was demonstrated in hematological malignancies. In the early 1990s, reports from China described impressive results with arsenic trioxide (ATO) in patients with relapsed and refractory acute promyelocytic leukemia (APL) (Zhang et al. 2001). Other investigators subsequently confirmed these results, leading to approval of its use for relapsed or refractory APL in the USA. Investigations of this agent have demonstrated that its efficacy in APL and preclinical tumor models is dependent upon a number of mechanisms, including induction of apoptosis, effects on cellular differentiation, cell cycling, and tumor angiogenesis (Emadi \& Gore 2010).

The mitotoxic properties of ATO also have been examined in solid tumors. In breast cancer cells, ATO reduced mitochondrial function through the inhibition of cytochrome $c$ oxidase (complex IV of the electron transport chain), and its cytotoxicity was correlated with strong suppression of the expression of c-Myc and HIF $1 \alpha$, and decreased the expression of the survival protein $\mathrm{Bcl} 2$ (Sun et al. 2011). In cervical cancer, ATO was effective against human papillomavirus (HPV)-infected cancer cell lines. It has been shown that ATO inhibited HPV-E6 protein expression, leading to upregulated p53 levels, induced S to G2/M arrest, and apoptosis (Wen et al. 2012). ATO inhibits the activation of hedgehog signaling and promotes apoptotic cell death in osteosarcoma cells by accumulation of DNA damage, and prevented the growth of osteosarcoma in nude mice (Nakamura et al. 2013).

In TC cells, ATO was investigated for its potential to increase iodide uptake. In transformed thyrocytes, ATO increased iodide uptake, inhibited proliferation, and induced apoptosis, therefore suggesting its potential usefulness for the treatment of radioiodine non-responsive differentiated thyroid carcinomas (Frohlich et al. 2008). Moreover, ATO affected metabolic activity and decreased glucose uptake in transformed thyrocytes. A recent study has demonstrated that a mitochondria-targeted drug was synergized with an inhibitor of glycolysis (2-deoxyglucose (2-DG)) to trigger breast cancer cell death (Cheng et al. 2012). In anaplastic TC cell lines, treatment with 2-deoxyglucose resulted in cytostatic effects, but did not induce apoptosis (Sandulache et al. 2012). Experiments in an animal model of anaplastic TC showed that 2-DG affected cancer cell metabolism. The magnitude of 2-DG effects on tumor metabolism, however, was small and its effective duration was limited. It is tempting to speculate that dual targeting of energy metabolism with mitochondrial drugs (ATO) and glycolytic inhibitors (2-DG) could be effective against anaplastic TC cells.

Currently, there are more than 100 clinical trials evaluating the usefulness of ATO for patients with various type of cancer, but no single trial for patients with TC (Clinicaltrials.gov).

\section{Summary}

The role of activating mutations in mitogenic RAS/RAF/ MEK/ERK and anti-apoptotic PI3K/AKT signaling pathways is well documented in TC. Efforts over the past decade to design targeted chemotherapy for BRAF, RET, and PI3K/AKT have shown narrow therapeutic effects, and

Table 1 List of pharmacotherapeutic agents with their described mechanism of action and cellular effects

\begin{tabular}{l} 
Agent \\
\hline Lithium \\
Valproic acid \\
Cannabinoids \\
Statins \\
Metformin \\
Nelfinavir \\
Chloroquine \\
Arsenic
\end{tabular}

Molecular targets
Notch, GSK3
HDAC
CB, ERK/TrkA
HMG-CoA reductase
AMPK, mTOR, ERK
AKT, HSP90
Lysosomal proteases
Mitochondrial complex IV

\section{Cellular effect}

Radio-sensitization, cell growth arrest

Re-differentiation

Cell growth arrest

Inhibition of cell growth and migration, re-differentiation

Cell growth arrest, radio-sensitization

ER stress, autophagy apoptosis

Autophagy, chemosensitization

Mitochondrial toxicity, apoptosis, necrosis

\section{Evidence in thyroid}

In vitro, in vivo, and human data In vitro, in vivo, and human data In vitro

In vitro, in vivo, and human data

In vitro, in vivo, and human data Not tested

In vitro

Not tested 
have not yet been proven to have widespread benefit in the treatment of TC patients. It has become evident that agents targeting signaling molecules often exhibit limited clinical activities. Biological redundancies and alternative pathways can often bypass the inhibition of a single target, suggesting that in some cases, broad-specificity compounds or multi-target drug therapies may be more effective than individual high-affinity, high-specificity therapies.

Experimental and clinical evidence shows that a number of widely used drugs for conditions other than cancer hit the same targets of known anti-cancer drugs with limited toxicity. We present herein the mechanistic allure of several therapies in the treatment of TC. In Table 1, we have summarized these agents with their proposed mechanism of action in relation to cellular effects in TC, as supported by both in vitro and in vivo evidence, as well as by studies in patients with thyroid disorders.

Several of these medications currently are being examined in clinical trials involving TC patients and can be quickly translated to the clinical practice. The results of studies demonstrating the anti-cancer effects of the metformin in patients with various types of cancer as well as data indicating the usefulness of metfromin in diabetic patients with TC strongly suggest that this anti-diabetic drug with a well-established safety profile could be quickly repositioned for the treatment of TC.

The provocative in vitro results with other medications need to be further confirmed in animal models of TC. The retrospective analysis of pathological data from patients with TC and concomitant pathologies requiring medical therapy (mood disorders, HIV, malaria, arsenic poison, and dyslipidemia) could provide important information regarding the potential utility of non-cancer medications for the management of TC.

Repositioning of established pharmacotherapeutic agents shows promise to open new treatment modalities leading to a broadened scope beyond current cancer therapeutic strategy. These diverse treatment choices could allow physicians to provide an individualized approach to optimize treatment for patients with TC.

\section{Declaration of interest}

The authors have nothing to disclose. The views presented in this manuscript are those of the authors; no endorsement by the USUHS or Department of Defense has been given or should be inferred.

\section{Funding}

This research did not receive any specific grant from any funding agency in the public, commercial or not-for-profit sector.

\section{References}

Adler JT, Hottinger DG, Kunnimalaiyaan M \& Chen H 2010 Inhibition of growth in medullary thyroid cancer cells with histone deacetylase inhibitors and lithium chloride. Journal of Surgical Research 159 640-644. (doi:10.1016/j.jss.2008.08.004)

Alfano L, Guida T, Provitera L, Vecchio G, Billaud M, Santoro M \& Carlomagno F 2010 RET is a heat shock protein 90 (HSP90) client protein and is knocked down upon HSP90 pharmacological block. Journal of Clinical Endocrinology and Metabolism 95 3552-3557. (doi:10.1210/jc.2009-2315)

Ashburn TT \& Thor KB 2004 Drug repositioning: identifying and developing new uses for existing drugs. Nature Reviews Drug Discovery 3 673-683. (doi:10.1038/nrd1468)

Baigent C, Keech A, Kearney PM, Blackwell L, Buck G, Pollicino C, Kirby A, Sourjina T, Peto R, Collins R et al. 2005 Efficacy and safety of cholesterol-lowering treatment: prospective meta-analysis of data from 90,056 participants in 14 randomised trials of statins. Lancet 366 1267-1278. (doi:10.1016/S0140-6736(05)67394-1)

Bardsley-Elliot A \& Plosker GL 2000 Nelfinavir: an update on its use in HIV infection. Drugs 59 581-620. (doi:10.2165/00003495-20005903000014)

Barrueto F Jr, Su M \& Nelson LS 2002 Valproic acid is a structural analog of GABA that enters various metabolic pathways and has many clinical effects. Journal of Emergency Medicine 23 303-304 author reply 304-305. (doi:10.1016/S0736-4679(02)00540-1)

Ben Sahra I, Le Marchand-Brustel Y, Tanti JF \& Bost F 2010 Metformin in cancer therapy: a new perspective for an old antidiabetic drug? Molecular Cancer Therapeutics 9 1092-1099. (doi:10.1158/1535-7163. MCT-09-1186)

Bocchetta A, Cocco F, Velluzzi F, Del Zompo M, Mariotti S \& Loviselli A 2007 Fifteen-year follow-up of thyroid function in lithium patients. Journal of Endocrinological Investigation 30 363-366.

Bolen S, Feldman L, Vassy J, Wilson L, Yeh HC, Marinopoulos S, Wiley C, Selvin E, Wilson R, Bass EB et al. 2007 Systematic review: comparative effectiveness and safety of oral medications for type 2 diabetes mellitus. Annals of Internal Medicine 147 386-399. (doi:10.7326/0003-4819-1476-200709180-00178)

Bruning A, Gingelmaier A, Friese K \& Mylonas I 2010 New prospects for nelfinavir in non-HIV-related diseases. Current Molecular Pharmacology 3 91-97. (doi:10.2174/1874-470211003020091)

Buchs AE \& Silverman BG 2011 Incidence of malignancies in patients with diabetes mellitus and correlation with treatment modalities in a large Israeli health maintenance organization: a historical cohort study. Metabolism 60 1379-1385. (doi:10.1016/j.metabol.2011.05.002)

Cappelli C, Castellano M, Pirola I, De Martino E, Gandossi E, Delbarba A, Salvi A \& Rosei EA 2008 Reduced thyroid volume and nodularity in dyslipidaemic patients on statin treatment. Clinical Endocrinology 68 16-21. (doi:10.1111/j.1365-2265.2007.02982.x)

Carlomagno F, Guida T, Anaganti S, Vecchio G, Fusco A, Ryan AJ, Billaud M \& Santoro M 2004 Disease associated mutations at valine 804 in the RET receptor tyrosine kinase confer resistance to selective kinase inhibitors. Oncogene 23 6056-6063. (doi:10.1038/sj.onc.1207810)

Catalano MG, Fortunati N, Pugliese M, Costantino L, Poli R, Bosco O \& Boccuzzi G 2005 Valproic acid induces apoptosis and cell cycle arrest in poorly differentiated thyroid cancer cells. Journal of Clinical Endocrinology and Metabolism 90 1383-1389. (doi:10.1210/jc.2004-1355)

Cazzaniga M, Bonanni B, Guerrieri-Gonzaga A \& Decensi A 2009 Is it time to test metformin in breast cancer clinical trials? Cancer Epidemiology, Biomarkers \& Prevention 18 701-705. (doi:10.1158/1055-9965. EPI-08-0871)

Chen G, Xu S, Renko K \& Derwahl M 2012 Metformin inhibits growth of thyroid carcinoma cells, suppresses self-renewal of derived cancer stem cells, and potentiates the effect of chemotherapeutic agents. Journal of Clinical Endocrinology and Metabolism 97 E510-E520. (doi:10.1210/jc. 2011-1754) 
Cheng G, Zielonka J, Dranka BP, McAllister D, Mackinnon AC Jr, Joseph J \& Kalyanaraman B 2012 Mitochondria-targeted drugs synergize with 2-deoxyglucose to trigger breast cancer cell death. Cancer Research 72 2634-2644. (doi:10.1158/0008-5472.CAN-11-3928)

Chiu CT, Wang Z, Hunsberger JG \& Chuang DM 2013 Therapeutic potential of mood stabilizers lithium and valproic acid: beyond bipolar disorder. Pharmacological Reviews 65 105-142. (doi:10.1124/pr.111. 005512)

Chung YS, Cho S, Ryou HJ, Jee HG, Choi JY, Yoon K, Choi HJ, Lee KE, Suh YJ, Oh SK et al. 2011 Is there a treatment advantage when paclitaxel and lovastatin are combined to dose anaplastic thyroid carcinoma cell lines? Thyroid 21 735-744. (doi:10.1089/thy.2010.0304)

Dickson M \& Gagnon JP 2004 The cost of new drug discovery and development. Discovery Medicine 4 172-179.

El-Mir MY, Nogueira V, Fontaine E, Averet N, Rigoulet M \& Leverve X 2000 Dimethylbiguanide inhibits cell respiration via an indirect effect targeted on the respiratory chain complex I. Journal of Biological Chemistry 275 223-228. (doi:10.1074/jbc.275.1.223)

Emadi A \& Gore SD 2010 Arsenic trioxide - an old drug rediscovered. Blood Reviews 24 191-199. (doi:10.1016/j.blre.2010.04.001)

Emig D, Ivliev A, Pustovalova O, Lancashire L, Bureeva S, Nikolsky Y \& Bessarabova M 2013 Drug target prediction and repositioning using an integrated network-based approach. PLoS ONE 8 e60618. (doi:10.1371/ journal.pone.0060618)

Evans M, Roberts A, Davies S \& Rees A 2004 Medical lipid-regulating therapy: current evidence, ongoing trials and future developments. Drugs 64 1181-1196. (doi:10.2165/00003495-200464110-00003)

Evans JM, Donnelly LA, Emslie-Smith AM, Alessi DR \& Morris AD 2005 Metformin and reduced risk of cancer in diabetic patients. BMJ 330 1304-1305. (doi:10.1136/bmj.38415.708634.F7)

Feng WH \& Kenney SC 2006 Valproic acid enhances the efficacy of chemotherapy in EBV-positive tumors by increasing lytic viral gene expression. Cancer Research 66 8762-8769. (doi:10.1158/0008-5472. CAN-06-1006)

Fortunati N, Catalano MG, Arena K, Brignardello E, Piovesan A \& Boccuzzi G 2004 Valproic acid induces the expression of the $\mathrm{Na}+$ / I- symporter and iodine uptake in poorly differentiated thyroid cancer cells. Journal of Clinical Endocrinology and Metabolism 89 1006-1009. (doi:10.1210/jc.2003-031407)

Fox R 1996 Anti-malarial drugs: possible mechanisms of action in autoimmune disease and prospects for drug development. Lupus 5 (Suppl 1) S4-10. (doi:10.1177/096120339600500103)

Frohlich E, Czarnocka B, Brossart P \& Wahl R 2008 Antitumor effects of arsenic trioxide in transformed human thyroid cells. Thyroid $\mathbf{1 8}$ 1183-1193. (doi:10.1089/thy.2008.0114)

Gills JJ, Lopiccolo J, Tsurutani J, Shoemaker RH, Best CJ, Abu-Asab MS, Borojerdi J, Warfel NA, Gardner ER, Danish M et al. 2007 Nelfinavir, a lead HIV protease inhibitor, is a broad-spectrum, anticancer agent that induces endoplasmic reticulum stress, autophagy, and apoptosis in vitro and in vivo. Clinical Cancer Research 13 5183-5194. (doi:10.1158/10780432.CCR-07-0161)

Goodwin PJ, Ligibel JA \& Stambolic V 2009 Metformin in breast cancer: time for action. Journal of Clinical Oncology 27 3271-3273. (doi:10.1200/ JCO.2009.22.1630)

Gottlicher M, Minucci S, Zhu P, Kramer OH, Schimpf A, Giavara S, Sleeman JP, Lo Coco F, Nervi C, Pelicci PG et al. 2001 Valproic acid defines a novel class of HDAC inhibitors inducing differentiation of transformed cells. EMBO Journal 20 6969-6978. (doi:10.1093/emboj/20.24.6969)

Greenblatt DY, Vaccaro AM, Jaskula-Sztul R, Ning L, Haymart M, Kunnimalaiyaan M \& Chen H 2007 Valproic acid activates notch-1 signaling and regulates the neuroendocrine phenotype in carcinoid cancer cells. Oncologist 12 942-951. (doi:10.1634/theoncologist. 12-8-942)

Hou P, Liu D, Shan Y, Hu S, Studeman K, Condouris S, Wang Y, Trink A El-Naggar AK, Tallini G et al. 2007 Genetic alterations and their relationship in the phosphatidylinositol 3-kinase/Akt pathway in

http://erc.endocrinology-journals.org DOI: 10.1530/ERC-13-0473
(C) 2014 Society for Endocrinology Printed in Great Britain thyroid cancer. Clinical Cancer Research 13 1161-1170. (doi:10.1158/ 1078-0432.CCR-06-1125)

Iliopoulos D, Hirsch HA \& Struhl K 2011 Metformin decreases the dose of chemotherapy for prolonging tumor remission in mouse xenografts involving multiple cancer cell types. Cancer Research 71 3196-3201. (doi:10.1158/0008-5472.CAN-10-3471)

Khurana R \& Malik IS 2010 Metformin: safety in cardiac patients. Heart 96 99-102.

Kim TH, Yoo YH, Kang DY, Suh H, Park MK, Park KJ \& Kim SH 2009 Efficacy on anaplastic thyroid carcinoma of valproic acid alone or in combination with doxorubicin, a synthetic chenodeoxycholic acid derivative, or lactacystin. International Journal of Oncology 34 1353-1362.

Kimura T, Takabatake Y, Takahashi A \& Isaka Y 2013 Chloroquine in cancer therapy: a double-edged sword of autophagy. Cancer Research 73 3-7. (doi:10.1158/0008-5472.CAN-12-2464)

Klubo-Gwiezdzinska J, Jensen K, Costello J, Patel A, Hoperia V, Bauer A, Burman KD, Wartofsky L \& Vasko V 2012 Metformin inhibits growth and decreases resistance to anoikis in medullary thyroid cancer cells. Endocrine-Related Cancer 19 447-456. (doi:10.1530/ERC-12-0046)

Klubo-Gwiezdzinska J, Costello J Jr, Patel A, Bauer A, Jensen K, Mete M, Burman KD, Wartofsky L \& Vasko V 2013 Treatment with metformin is associated with higher remission rate in diabetic patients with thyroid cancer. Journal of Clinical Endocrinology and Metabolism 98 3269-3279. (doi:10.1210/jc.2012-3799)

Koomen ER, Joosse A, Herings RM, Casparie MK, Bergman W, Nijsten T \& Guchelaar HJ 2007 Is statin use associated with a reduced incidence, a reduced Breslow thickness or delayed metastasis of melanoma of the skin? European Journal of Cancer 43 2580-2589. (doi:10.1016/j.ejca. 2007.09.004)

Koong SS, Reynolds JC, Movius EG, Keenan AM, Ain KB, Lakshmanan MC \& Robbins J 1999 Lithium as a potential adjuvant to 131I therapy of metastatic, well differentiated thyroid carcinoma. Journal of Clinical Endocrinology and Metabolism 84 912-916. (doi:10.1210/jcem.84.3. 5527)

Kroemer G, Marino G \& Levine B 2010 Autophagy and the integrated stress response. Molecular Cell 40 280-293. (doi:10.1016/j.molcel.2010. 09.023)

Kunnimalaiyaan M, Vaccaro AM, Ndiaye MA \& Chen H 2007 Inactivation of glycogen synthase kinase-3 $\beta$, a downstream target of the raf- 1 pathway, is associated with growth suppression in medullary thyroid cancer cells. Molecular Cancer Therapeutics 6 1151-1158. (doi:10.1158/ 1535-7163.MCT-06-0665)

Laezza C, Fiorentino L, Pisanti S, Gazzerro P, Caraglia M, Portella G, Vitale M \& Bifulco M 2008 Lovastatin induces apoptosis of k-rastransformed thyroid cells via inhibition of ras farnesylation and by modulating redox state. Journal of Molecular Medicine 86 1341-1351. (doi:10.1007/s00109-008-0396-1)

Lanzi C, Cassinelli G, Nicolini V \& Zunino F 2009 Targeting RET for thyroid cancer therapy. Biochemical Pharmacology 77 297-309. (doi:10.1016/ j.bcp.2008.10.033)

Lee MS, Hsu CC, Wahlqvist ML, Tsai HN, Chang YH \& Huang YC 2011 Type 2 diabetes increases and metformin reduces total, colorectal, liver and pancreatic cancer incidences in Taiwanese: a representative population prospective cohort study of 800,000 individuals. $B M C$ Cancer 11 20. (doi:10.1186/1471-2407-11-20)

Li YY \& Jones SJ 2012 Drug repositioning for personalized medicine. Genome Medicine 4 27. (doi:10.1186/1755-8794-4-27)

Liebner DA \& Shah MH 2011 Thyroid cancer: pathogenesis and targeted therapy. Therapeutic Advances in Endocrinology and Metabolism 2 173-195. (doi:10.1177/2042018811419889)

Lin CI, Whang EE, Abramson MA, Jiang X, Price BD, Donner DB, Moore FD Jr \& Ruan DT 2009 Autophagy: a new target for advanced papillary thyroid cancer therapy. Surgery 146 1208-1214. (doi:10.1016/j.surg. 2009.09.019) 
Lin CI, Whang EE, Donner DB, Du J, Lorch J, He F, Jiang X, Price BD, Moore FD Jr \& Ruan DT 2010 Autophagy induction with RAD001 enhances chemosensitivity and radiosensitivity through Met inhibition in papillary thyroid cancer. Molecular Cancer Research 8 1217-1226. (doi:10.1158/1541-7786.MCR-10-0162)

Lin CI, Whang EE, Lorch JH \& Ruan DT 2012 Autophagic activation potentiates the antiproliferative effects of tyrosine kinase inhibitors in medullary thyroid cancer. Surgery 152 1142-1149. (doi:10.1016/j.surg. 2012.08.016)

Mancias JD \& Kimmelman AC 2011 Targeting autophagy addiction in cancer. Oncotarget 2 1302-1306.

Martin-Castillo B, Vazquez-Martin A, Oliveras-Ferraros C \& Menendez JA 2010 Metformin and cancer: doses, mechanisms and the dandelion and hormetic phenomena. Cell Cycle 9 1057-1064. (doi:10.4161/cc.9.6. 10994)

Mitmaker EJ, Griff NJ, Grogan RH, Sarkar R, Kebebew E, Duh QY, Clark OH \& Shen WT 2011 Modulation of matrix metalloproteinase activity in human thyroid cancer cell lines using demethylating agents and histone deacetylase inhibitors. Surgery 149 504-511. (doi:10.1016/ j.surg.2010.10.007)

Modigliani E, Cohen R, Campos JM, Conte-Devolx B, Maes B, Boneu A, Schlumberger M, Bigorgne JC, Dumontier P, Leclerc L et al. 1998 Prognostic factors for survival and for biochemical cure in medullary thyroid carcinoma: results in 899 patients. The GETC Study Group. Groupe d'etude des tumeurs a calcitonine. Clinical Endocrinology $\mathbf{4 8}$ 265-273. (doi:10.1046/j.1365-2265.1998.00392.x)

Nakagawa M, Oda Y, Eguchi T, Aishima S, Yao T, Hosoi F, Basaki Y, Ono M, Kuwano M, Tanaka M et al. 2007 Expression profile of class I histone deacetylases in human cancer tissues. Oncology Reports 18 769-774.

Nakamura S, Nagano S, Nagao H, Ishidou Y, Yokouchi M, Abematsu M, Yamamoto T, Komiya S \& Setoguchi T 2013 Arsenic trioxide prevents osteosarcoma growth by inhibition of GLI transcription via DNA damage accumulation. PLOS ONE 8 e69466. (doi:10.1371/journal.pone. 0069466)

Nikiforov YE 2008 Thyroid carcinoma: molecular pathways and therapeutic targets. Modern Pathology 21 (Suppl 2) S37-S43. (doi:10.1038/modpathol.2008.10)

O'Connor KA \& Roth BL 2005 Finding new tricks for old drugs: an efficient route for public-sector drug discovery. Nature Reviews Drug Discovery 4 1005-1014. (doi:10.1038/nrd1900)

Pan J, Mott M, Xi B, Hepner E, Guan M, Fousek K, Magnusson R, Tinsley R, Valdes F, Frankel P et al. 2012 Phase I study of nelfinavir in liposarcoma. Cancer Chemotherapy and Pharmacology 70 791-799. (doi:10.1007/ s00280-012-1961-4)

Perez G, MacArthur RD, Walmsley S, Baxter JA, Mullin C \& Neaton JD 2004 A randomized clinical trial comparing nelfinavir and ritonavir in patients with advanced HIV disease (CPCRA 042/CTN 102). HIV Clinical Trials 5 7-18. (doi:10.1310/N11F-NK93-MUMR-A1VV)

Petrushev B, Tomuleasa C, Soritau O, Aldea M, Pop T, Susman S, Kacso G, Berindan I, Irimie A \& Cristea V 2012 Metformin plus PIAF combination chemotherapy for hepatocellular carcinoma. Experimental Oncology 34 17-24.

Pons F, Carrio I, Estorch M, Ginjaume M, Pons J \& Milian R 1987 Lithium as an adjuvant of iodine-131 uptake when treating patients with well-differentiated thyroid carcinoma. Clinical Nuclear Medicine 12 644-647. (doi:10.1097/00003072-198708000-00014)

Pore N, Gupta AK, Cerniglia GJ, Jiang Z, Bernhard EJ, Evans SM, Koch CJ, Hahn SM \& Maity A 2006 Nelfinavir down-regulates hypoxia-inducible factor $1 \alpha$ and VEGF expression and increases tumor oxygenation: implications for radiotherapy. Cancer Research 66 9252-9259. (doi:10.1158/0008-5472.CAN-06-1239)

Puppin C, D'Aurizio F, D'Elia AV, Cesaratto L, Tell G, Russo D, Filetti S, Ferretti E, Tosi E, Mattei T et al. 2005 Effects of histone acetylation on sodium iodide symporter promoter and expression of thyroid-specific transcription factors. Endocrinology 146 3967-3974. (doi:10.1210/en. 2005-0128)
Rask-Andersen M, Almen MS \& Schioth HB 2011 Trends in the exploitation of novel drug targets. Nature Reviews Drug Discovery 10 579-590. (doi:10.1038/nrd3478)

Rengan R, Mick R, Pryma D, Rosen MA, Lin LL, Maity AM, Evans TL, Stevenson JP, Langer CJ, Kucharczuk J et al. 2012 A phase I trial of the HIV protease inhibitor nelfinavir with concurrent chemoradiotherapy for unresectable stage IIIA/IIIB non-small cell lung cancer: a report of toxicities and clinical response. Journal of Thoracic Oncology 7 709-715. (doi:10.1097/JTO.0b013e3182435aa6)

Rezzonico J, Rezzonico M, Pusiol E, Pitoia F \& Niepomniszcze H 2011 Metformin treatment for small benign thyroid nodules in patients with insulin resistance. Metabolic Syndrome and Related Disorders 9 69-75. (doi:10.1089/met.2010.0026)

Ringel MD 2000 Molecular diagnostic tests in the diagnosis and management of thyroid carcinoma. Reviews in Endocrine \& Metabolic Disorders 1 173-181. (doi:10.1023/A:1010027014324)

Ringel MD 2009 Molecular markers of aggressiveness of thyroid cancer. Current Opinion in Endocrinology, Diabetes and Obesity 16 361-366. (doi:10.1097/MED.0b013e32832ff2cb)

Rocha GZ, Dias MM, Ropelle ER, Osorio-Costa F, Rossato FA, Vercesi AE, Saad MJ \& Carvalheira JB 2011 Metformin amplifies chemotherapyinduced AMPK activation and antitumoral growth. Clinical Cancer Research 17 3993-4005. (doi:10.1158/1078-0432.CCR-10-2243)

Rueda D, Navarro B, Martinez-Serrano A, Guzman M \& Galve-Roperh I 2002 The endocannabinoid anandamide inhibits neuronal progenitor cell differentiation through attenuation of the Rap1/B-Raf/ERK pathway. Journal of Biological Chemistry 277 46645-46650. (doi:10. 1074/jbc.M206590200)

Salazar M, Carracedo A, Salanueva IJ, Hernandez-Tiedra S, Egia A, Lorente M, Vazquez P, Torres S, Iovanna JL, Guzman M et al. 2009 TRB3 links ER stress to autophagy in cannabinoid anti-tumoral action. Autophagy 5 1048-1049. (doi:10.4161/auto.5.7.9508)

Sandulache VC, Skinner HD, Wang Y, Chen Y, Dodge CT, Ow TJ, Bankson JA, Myers JN \& Lai SY 2012 Glycolytic inhibition alters anaplastic thyroid carcinoma tumor metabolism and improves response to conventional chemotherapy and radiation. Molecular Cancer Therapeutics 11 1373-1380. (doi:10.1158/1535-7163.MCT12-0041)

Schlumberger MJ 1998 Papillary and follicular thyroid carcinoma. New England Journal of Medicine 338 297-306. (doi:10.1056/ NEJM199801293380506)

Shaw RJ 2009 LKB1 and AMP-activated protein kinase control of mTOR signalling and growth. Acta Physiologica 196 65-80. (doi:10.1111/ j.1748-1716.2009.01972.x)

Shen WT, Wong TS, Chung WY, Wong MG, Kebebew E, Duh QY \& Clark $\mathrm{OH} 2005$ Valproic acid inhibits growth, induces apoptosis, and modulates apoptosis-regulatory and differentiation gene expression in human thyroid cancer cells. Surgery 138 979-984 discussion 984-975. (doi:10.1016/j.surg.2005.09.019)

Shi Y, Zou M, Baitei EY, Alzahrani AS, Parhar RS, Al-Makhalafi Z \& Al-Mohanna FA 2008 Cannabinoid 2 receptor induction by IL-12 and its potential as a therapeutic target for the treatment of anaplastic thyroid carcinoma. Cancer Gene Therapy 15 101-107. (doi:10.1038/ sj.cgt.7701101)

Shim JS, Rao R, Beebe K, Neckers L, Han I, Nahta R \& Liu JO 2012 Selective inhibition of HER2-positive breast cancer cells by the HIV protease inhibitor nelfinavir. Journal of the National Cancer Institute $\mathbf{1 0 4}$ 1576-1590. (doi:10.1093/jnci/djs396)

Shimakage M, Kawahara K, Sasagawa T, Inoue H, Yutsudo M, Yoshida A \& Yanoma S 2003 Expression of Epstein-Barr virus in thyroid carcinoma correlates with tumor progression. Human Pathology 34 1170-1177. (doi:10.1053/j.humpath.2003.07.001)

Sun RC, Board PG \& Blackburn AC 2011 Targeting metabolism with arsenic trioxide and dichloroacetate in breast cancer cells. Molecular Cancer 10 142. (doi:10.1186/1476-4598-10-142) 
Urabe M, Hershman JM, Pang XP, Murakami S \& Sugawara M 1991 Effect of lithium on function and growth of thyroid cells in vitro. Endocrinology 129 807-814. (doi:10.1210/endo-129-2-807)

Vara D, Salazar M, Olea-Herrero N, Guzman M, Velasco G \& Diaz-Laviada I 2011 Anti-tumoral action of cannabinoids on hepatocellular carcinoma: role of AMPK-dependent activation of autophagy. Cell Death and Differentiation 18 1099-1111. (doi:10.1038/cdd.2011.32)

Vigersky RA, Filmore-Nassar A \& Glass AR 2006 Thyrotropin suppression by metformin. Journal of Clinical Endocrinology and Metabolism 91 225-227. (doi:10.1210/jc.2005-1210)

Wang CY, Zhong WB, Chang TC, Lai SM \& Tsai YF 2003 Lovastatin, a 3-hydroxy-3-methylglutaryl coenzyme A reductase inhibitor, induces apoptosis and differentiation in human anaplastic thyroid carcinoma cells. Journal of Clinical Endocrinology and Metabolism 88 3021-3026. (doi:10.1210/jc.2002-021834)

Wang CY, Shui HA \& Chang TC 2010 In vivo evidence of duality effects for lovastatin in a nude mouse cancer model. International Journal of Cancer 126 578-582. (doi:10.1002/ijc.24760)

Wang Y, Peng RQ, Li DD, Ding Y, Wu XQ, Zeng YX, Zhu XF \& Zhang XS 2011 Chloroquine enhances the cytotoxicity of topotecan by inhibiting autophagy in lung cancer cells. Chinese Journal of Cancer $\mathbf{3 0}$ 690-700. (doi:10.5732/cjc.011.10056)

Wen X, Li D, Zhang Y, Liu S, Ghali L \& Iles RK 2012 Arsenic trioxide induces cervical cancer apoptosis, but specifically targets human papillomavirus-infected cell populations. Anticancer Drugs 23 280-287. (doi:10.1097/CAD.0b013e32834f1fd3)

Xing M, Westra WH, Tufano RP, Cohen Y, Rosenbaum E, Rhoden KJ, Carson KA, Vasko V, Larin A, Tallini G et al. 2005 BRAF mutation predicts a poorer clinical prognosis for papillary thyroid cancer. Journal of Clinical Endocrinology and Metabolism 90 6373-6379. (doi:10.1210/jc.2005-0987)

Xu WS, Parmigiani RB \& Marks PA 2007 Histone deacetylase inhibitors: molecular mechanisms of action. Oncogene 26 5541-5552. (doi:10.1038/sj.onc.1210620)

Yang Y, Ikezoe T, Nishioka C, Bandobashi K, Takeuchi T, Adachi Y, Kobayashi M, Takeuchi S, Koeffler HP \& Taguchi H 2006 NFV, an HIV-1 protease inhibitor, induces growth arrest, reduced Akt signalling, apoptosis and docetaxel sensitisation in NSCLC cell lines. British Journal of Cancer 95 1653-1662. (doi:10.1038/sj.bjc.6603435)

Yasunari K, Maeda K, Minami M \& Yoshikawa J 2001 HMG-CoA reductase inhibitors prevent migration of human coronary smooth muscle cells through suppression of increase in oxidative stress. Arteriosclerosis, Thrombosis, and Vascular Biology 21 937-942. (doi:10.1161/01.ATV. 21.6.937)

Zeybek ND, Gulcelik NE, Kaymaz FF, Sarisozen C, Vural I, Bodur E, Canpinar H, Usman A \& Asan E 2011 Rosuvastatin induces apoptosis in cultured human papillary thyroid cancer cells. Journal of Endocrinological Investigation 210 105-115.

Zhang TD, Chen GQ, Wang ZG, Wang ZY, Chen SJ \& Chen Z 2001 Arsenic trioxide, a therapeutic agent for APL. Oncogene 20 7146-7153. (doi:10.1038/sj.onc.1204762)

Zhang L, He M, Zhang Y, Nilubol N, Shen M \& Kebebew E 2012 Quantitative high-throughput drug screening identifies novel classes of drugs with anticancer activity in thyroid cancer cells: opportunities for repurposing. Journal of Clinical Endocrinology and Metabolism 97 E319-E328. (doi:10.1210/jc.2011-2671)

Received in final form 3 January 2014

Accepted 17 January 2014

Made available online as an Accepted Preprint

20 January 2014
(C) 2014 Society for Endocrinology Printed in Great Britain 